\title{
Preservation and development of Giao Co Lam (Gynostemma pentaphyllum) in the hot tropics of Vietnam
}

\author{
Pham Cao Khai, Tran Van Minh
}

\begin{abstract}
The internode segments of Giao Co Lam (Gynostemma pentaphyllum) sterilized with diluted solution of javel (50\%) for 20 minutes reached to $73.33 \%$ sterile explants. In vitro cutting stem segments of Giao Co Lam cultured on MS medium supplemented with $1.0 \mathrm{mg} / \mathrm{L} \mathrm{BA}$ and $0.1 \mathrm{mg} / \mathrm{L} \mathrm{NAA}$ gave the highest shoot induction ( 6.8 shoots/ explant). The regenerated shoots cultured on MS $1 / 2$ medium were suitable for growth of shoots with $5.2 \mathrm{~cm}$ in height and 4.0 leaves per plantlet. For root induction, the MS $1 / 2$ medium supplemented with $0.25 \mathrm{mg} / \mathrm{L} \mathrm{IBA}$ was appropriate and the root length could be in $7.6 \mathrm{~cm}$ in this medium. The rate of survival plantlets is $85 \%$ in garden.
\end{abstract}

Keywords-Gynostemma pentaphyllum, multiplication of Giao Co Lam, medicinal plant, shoot proliferation

\section{Introduction}

Gynostemma pentaphyllum known as medicinal herb is famous for the anti-stress properties, restoring the body's balance and improving the memory. It contains more than 100 kinds of dammarane-type triterpenoid saponins. The number of saponins in Giao Co Lam is more than 3 - 4 times of those of ginseng. Besides, It contains many vitamins, minerals, trace elements, amino acids and proteins (Huang et al., 2008a; Razmovski-Naumovski et al., 2005). According to Kiem et al. (2009), Giao Co Lam (GCL) enhances the lipid metabolism led to stabilize cholesterol levels in the blood and reduce the fat effectively; balance the blood pressure; prevent the thrombosis, the cardiovascular and brain complications, anti-aging; increase the appetite and good sleep. In addition, Giao Co Lam increases the immunity and inhibits the growth of tumors significantly (Blumert \& Liu, 1999).

In the research of the scientists in Vietnam National Institute of Medicinal Materials and Swedish Karolinska Institute on Giao Co Lam, a new substance had been found and named as Phanoside. This substance has the strong hypoglycemic effect, stimulates the insulin secretion of pancreas and increases the sensitivity of target cells to insulin (Norberg et al., 2004).

Pham Cao Khai

Research and development Center for High-Tech Agriculture, Agricultural High-Tech Park of Ho Chi Minh City

Viet Nam
Furthermore, Phan Van Kiem et al. (2009) in Korea had extracted the active ingredients of gypenosides in Giao Co Lam Vietnam and tested on the tumors in lung, colon, breast, uterus, prostate with very good results. The new bioactive is capable of inhibiting and killing the aforementioned cancer cells and improving the immune system of the body.

With many pharmaceutical effects above, Giao Co Lam has been using in the production of drugs and functional foods. Therefore, the source of wild GCL has been overexploited. There have been some studies of GCL breeding applying traditional techniques such as cuttings, sowings, etc. however the propagation coefficient and uniformity of plant is low. Plant tissue culture techniques play an important role in the conservation and breeding of crops, especially valuable medicinal plants. This study aims to determine the feasibility of internode culture techniques for establishing the technical process of GCL micropropagation (Gynostemma pentaphyllum), a source of medicinal materials in the production of pharmaceuticals.

\section{Materials and methods}

\section{A. Materials}

The 1-year-old internodes of GCL originated from Lang Son was acclimatized and grown in $\mathrm{Cu}$ Chi district, Ho Chi Minh City, Viet Nam.

The experimental media included micro and macro minerals of MS medium (Murashige, Skoog, 1962), vitamin, sucrose, agar, BA (benzyl aminopurin), NAA (naphthalenacetic acid) and IBA (indolbutyric acid). The $\mathrm{pH}$ of media was adjusted to 5.8 before autoclaving at $121{ }^{\circ} \mathrm{C}, 1$ atm for 20 minutes.

Experimental conditions: The experiments were maintained under 16 hours/day in lighting period, 2,000 lux in light intensity, $24 \pm 2{ }^{\circ} \mathrm{C}$ in temperature; $75-80 \%$ in average humidity.

\section{B. Methods}

The experiments were arranged in a completely randomized design (CRD) with 3 replications. Each treatment was cultured 15 explants. Data was recorded after 6 weeks of culture and subjected to analysis of variance with the MSTATC statistical software package.

\section{Experimental design}

Experiment 1. The examination of the concentrations of Javel solution $(\mathrm{NaOCl} 5 \%)$ and treatment time on the rate of sterile explants: The $3 \mathrm{~cm}$-long internodes have been moved 
Proc. of The Sixth Intl. Conf. On Advances in Applied Science and Environmental Technology - ASET 2017 Copyright $@$ Institute of Research Engineers and Doctors, USA .All rights reserved.

ISBN: 978-1-63248-119-1 doi: 10.15224/ 978-1-63248-119-1-36

into the laminar flow bench, washed with the bleach solution in 10 minutes, and then rinsed with sterile distilled water. Subsequently, those were disinfected with ethanol $70 \%$ in 1 minute, followed by the different concentrations of Javel solution $(50 \%$ and $100 \%)$ added with several drops of Tween- 80 in different periods (10, 15, and 20 minutes) and rinsed with sterile distilled water. After sterilization of the explants, the necrotic portions of internodes were removed and cultured on MS medium without plant growth regulators. The treatments were arranged in a completely randomized design (CRD) with 3 replications. This experiment consisted of six treatments and each treatment was cultured 15 explants. Observation and record of results was carried out after 2 weeks of culture.

Experiment 2. The effects of BA and NAA concentrations on the shoot multiplication: The in vitro internodes with approximately 1.5 to $2 \mathrm{~cm}$ in size were cultured on MS media added with sucrose $20 \mathrm{~g} / \mathrm{L}$, agar 8 $\mathrm{g} / \mathrm{L}, \mathrm{BA}(0.1,0.5,1.0,1,5,2.0 \mathrm{mg} / \mathrm{L})$ in combination with NAA $(0,0.1,0.2,0.3 \mathrm{mg} / \mathrm{L})$. The experiment was arranged in a completely randomized design (CRD) with 3 replications. This experiment consisted of 24 treatments and each treatment was cultured 15 explants. Observation and record of results was carried out after 6 weeks of culture.

Experiment 3. The effects of mineral media on the growth of shoots: The in vitro $2 \mathrm{~cm}$-long shoots were cultured on different mineral media: MS, MS 1/2 (half of macro minerals), $1 / 2 \mathrm{MS}$ (half of macro and micro minerals), and KC (Knudson C) added with sucrose $20 \mathrm{~g} / \mathrm{L}$, agar $8 \mathrm{~g} / \mathrm{L}$. The experiment was arranged in a completely randomized design (CRD) with 3 replications. This experiment consisted of four treatments and each treatment was cultured 15 explants. Observation and record of results was carried out after 6 weeks of culture.

Experiment 4. The effects of IBA concentrations on the root formation: The in vitro $2 \mathrm{~cm}$-long shoots were cultured on optimal mineral media (determined in content 3 ) added with sucrose $20 \mathrm{~g} / \mathrm{L}$, agar $8 \mathrm{~g} / \mathrm{L}$, and IBA $(0,0.25,0.5,1.0$ $\mathrm{mg} / \mathrm{L})$. The experiment was arranged in a completely randomized design (CRD) with 3 replications. This experiment consisted of four treatments and each treatment was cultured 15 explants. Observation and record of results was carried out after 6 weeks of culture.

\section{Results and discussion}

\section{A. The effect of the Javel concentrations and treatment time on the sterilization of explants}

The sterilization of explants with Javel solution $(\mathrm{NaOCl}$ $0.5 \%$ ) in 2 concentrations including $50 \%$ (diluted with sterile distilled water) and $100 \%$ in 10 minutes, 15 minutes and 20 minutes showed that the rate of sterile explants gained from $0-73.33 \%$. The explants sterilized with Javel solution at a concentration of $50 \%$ during 20 minutes gained the highest rate of sterile explants $(73.33 \%)$ compared to the other treatments (Table 1). However, this result is statistically insignificantly different compared with that of the treatment disinfected with a javel solution at a
TABLE 1. EFFECT OF JAVEL CONCENTRATIONS AND TREATMENT TIME ON RATE OF ASEPTIC EXPLANTS

\begin{tabular}{|c|c|c|}
\hline $\begin{array}{c}\text { Concentration } \\
\text { of javel }\end{array}$ & $\begin{array}{c}\text { Treatment time } \\
\text { (minutes) }\end{array}$ & $\begin{array}{c}\text { Rate of aseptic } \\
\text { explants }(\%)\end{array}$ \\
\hline \multirow[t]{3}{*}{ Javel (50\%) } & 10 & $20.00^{\text {bc }}$ \\
\hline & 15 & $60.00^{\mathrm{ab}}$ \\
\hline & 20 & $\mathbf{7 3 . 3 3}^{\mathrm{a}}$ \\
\hline \multirow[t]{3}{*}{ Javel (100\%) } & 10 & $20.00^{\mathrm{bc}}$ \\
\hline & 15 & $6.67^{\mathrm{c}}$ \\
\hline & 20 & $0.00^{c}$ \\
\hline CV (\%) & & 7.536 \\
\hline
\end{tabular}

concentration of $50 \%$ during 10 minutes with the rate of sterile explants reached $60.00 \%$. Therefore, the commercial Javel solution (Hypochlorite-Na 5\%) is suitable for disinfection of fungi and bacteria penetrating on the surface and tissue of the explants. The sterilization of explants at a concentration of $50 \%$ javel in 15 to 20 minutes is appropriate for internodes of Giao Co Lam.

\section{B. The effect of $B A$ and NAA concentrations on shoot multiplication}

The in vitro internodes cultured on MS medium supplemented with BA and NAA in different concentrations showed that: The explants in all treatments induced the shoot formation with callus and roots after culturing in 6 weeks. On the MS medium without growth regulators, some explants also formed shoot induction and growth after 6 weeks of culture. However, the treatment of growth regulators with $1.0 \mathrm{mg} / \mathrm{L} \mathrm{BA}$ and $0.1 \mathrm{mg} / \mathrm{L} \mathrm{NAA}$ is optimal for shoot proliferation (6.8 shoots/explant) (Table 2) (Figure 1-2). In this treatment, the shoots did not generate roots and formed little callus.

TABLE 2. EFFECT OF BA AND NAA ON SHOOT PROLIFERATION OF GIAO CO LAM

\begin{tabular}{|c|c|c|c|}
\hline NAA & BA & $\begin{array}{c}\text { Rate of shoot-formed } \\
\text { explants (\%) }\end{array}$ & $\begin{array}{c}\text { Shoot number } \\
\text { (shoots/explants) }\end{array}$ \\
\hline 0 & 0.1 & $49.7^{\mathrm{fg}}$ & $1.0^{\mathrm{j}}$ \\
\hline 0 & 0.5 & $86.3^{\mathrm{bc}}$ & $4.2^{\mathrm{cd}}$ \\
\hline 0 & 1.0 & $80.3^{\mathrm{d}}$ & $3.0^{\mathrm{e}}$ \\
\hline 0 & 1.5 & $53.3^{\mathrm{f}}$ & $2.7^{\mathrm{e}}$ \\
\hline 0 & 2.0 & $41.7^{\mathrm{hi}}$ & $0.6^{\mathrm{jj}}$ \\
\hline 0.1 & 0.1 & $39.7^{\mathrm{ij}}$ & $0.6^{\mathrm{jj}}$ \\
\hline 0.1 & 0.5 & $96.3^{\mathrm{a}}$ & $4.4^{\mathrm{c}}$ \\
\hline $\mathbf{0 . 1}$ & $\mathbf{1 . 0}$ & $\mathbf{1 0 0 . 0}^{\mathrm{a}}$ & $\mathbf{6 . 8}^{\mathrm{a}}$ \\
\hline 0.1 & 1.5 & $78.7^{\mathrm{d}}$ & $3.0^{\mathrm{e}}$ \\
\hline 0.1 & 2.0 & $51.3^{\mathrm{fg}}$ & $1.5^{\mathrm{gh}}$ \\
\hline 0.2 & 0.1 & $35.7^{\mathrm{j}}$ & $0.5^{\mathrm{j}}$ \\
\hline 0.2 & 0.5 & $76.3^{\mathrm{d}}$ & $3.0^{\mathrm{e}}$ \\
\hline 0.2 & 1.0 & $80.0^{\mathrm{d}}$ & $3.8^{\mathrm{d}}$ \\
\hline 0.2 & 1.5 & $88.7^{\mathrm{b}}$ & $5.2^{\mathrm{b}}$ \\
\hline 0.2 & 2.0 & $49.3^{\mathrm{fg}}$ & $1.8^{\mathrm{fg}}$ \\
\hline 0.3 & 0.1 & $45.7^{\mathrm{gh}}$ & $1.1^{\mathrm{hi}}$ \\
\hline 0.3 & 0.5 & $46.3^{\mathrm{gh}}$ & $2.7^{\mathrm{e}}$ \\
\hline 0.3 & 1.0 & $78.0^{\mathrm{d}}$ & $3.2^{\mathrm{e}}$ \\
\hline 0.3 & 1.5 & $80.7^{\mathrm{cd}}$ & $5.4^{\mathrm{b}}$ \\
\hline 0.3 & 2.0 & $59.3^{\mathrm{e}}$ & $2.2^{\mathrm{f}}$ \\
\hline CV $(\%)$ & 3.95 & 7.48 \\
\hline
\end{tabular}

* Means followed by same letters within a column are not significantly different according to Duncan's Multiple Range Test at $\mathrm{P} \leq 0.05$ level. 
Proc. of The Sixth Intl. Conf. On Advances in Applied Science and Environmental Technology - ASET 2017 Copyright (C) Institute of Research Engineers and Doctors, USA .All rights reserved.

ISBN: 978-1-63248-119-1 doi: 10.15224/ 978-1-63248-119-1-36

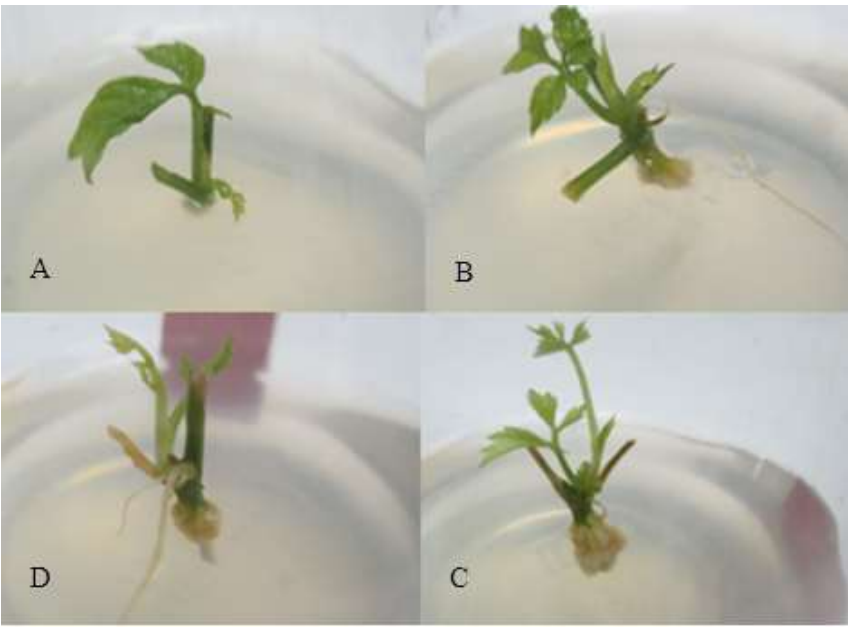

Figure 1. The shoot induction of Giao Co Lam internodes on the media supplemented with NAA and BA in different concentrations after 2 weeks of culture. (A) Control, (B) BA $1 \mathrm{mg} / \mathrm{L}+\mathrm{NAA} 0.1 \mathrm{mg} / \mathrm{L}$, (C) BA $1 \mathrm{mg} / \mathrm{L}$ + NAA $0.3 \mathrm{mg} / \mathrm{L}$ (D) BA $2 \mathrm{mg} / \mathrm{L}+$ NAA $0.1 \mathrm{mg} / \mathrm{L}$

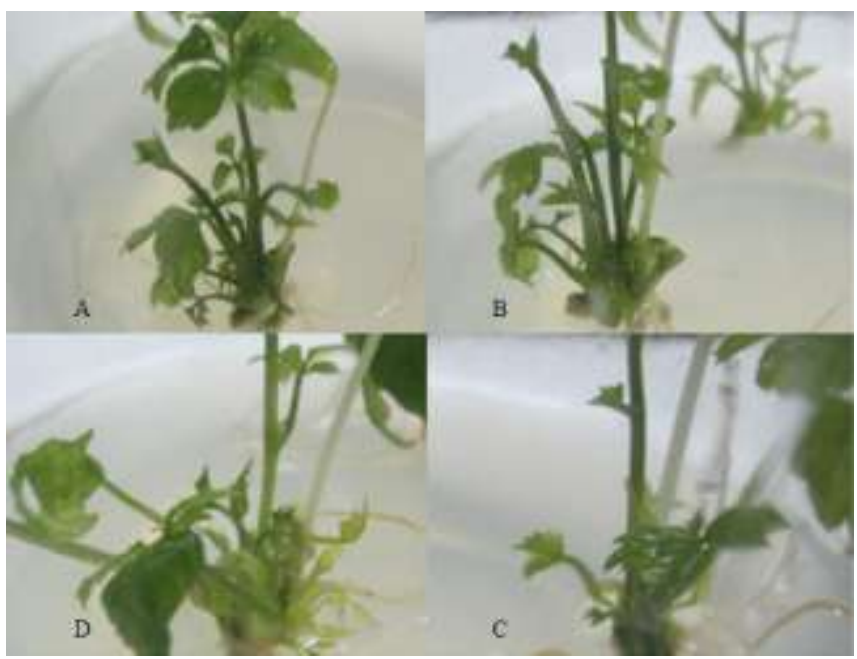

Figure 2. The shoot induction of internodes on the media supplemented with NAA and BA in different concentrations after 6 weeks of culture. (A) BA $1 \mathrm{mg} / \mathrm{L}$ + NAA $0.1 \mathrm{mg} / \mathrm{L}$, (B) BA $1.5 \mathrm{mg} / \mathrm{L}$ + NAA $0.1 \mathrm{mg} / \mathrm{L},(\mathrm{C}) \mathrm{BA}$ $1.5 \mathrm{mg} / \mathrm{L}+$ NAA $0.2 \mathrm{mg} / \mathrm{L}$, (D) BA $2 \mathrm{mg} / \mathrm{L}+$ NAA $0.3 \mathrm{mg} / \mathrm{L}$

The result of this study is similar with that of others (Zhang et al., 1989). The node segments of Giao Co Lam induced shoot multiplication best on MS medium supplemented with BA $1.0 \mathrm{mg} / \mathrm{L}$ and IAA $0.05 \mathrm{mg} / \mathrm{L}$. Another study of Giao Co Lam multiplication (Gynostemma pentaphyllum) on MS medium supplemented with BA (1.0 $\mathrm{mg} / \mathrm{L})$ and IAA $(0.5 \mathrm{mg} / \mathrm{L})$ is best (Shi et al., 2007). According to Lam et al. (2015), in vitro propagation of Giao Co Lam is best on MS medium supplemented with Kinetine $(0.4 \mathrm{mg} / \mathrm{L})$ and BA $(0.5 \mathrm{mg} / \mathrm{L})$ and the coefficient of shoot multiplication reached 4.36 times (small buds, dark green) lower than that of this study.

\section{Effect of mineral media on the growth of in vitro shoots}

After the shoot proliferation is the growth phase, thus the medium component is an important factor to ensure the standard and quality of plantlets which easily adapt to external conditions in the period of post-tissue culture. For each different species of plant, the different demand of mineral compositions determined is essential. The experiment was conducted by selecting $2 \mathrm{~cm}$-long shoots and culturing in the experimental media after 6 weeks of culture. The collected results are shown in Table 3:

TABLE 3. EFFECT OF MINERAL MEDIA ON THE GROWTH OF IN VITRO SHOOTS.

\begin{tabular}{|c|c|c|c|}
\hline Treatments & Mineral media & $\begin{array}{c}\text { Height of shoots } \\
(\mathbf{c m})\end{array}$ & $\begin{array}{c}\text { Leaf } \\
\text { Number }\end{array}$ \\
\hline M0 & MS & $3.4^{\mathrm{b}}$ & $2.8^{\mathrm{b}}$ \\
\hline M1 & MS 1/2 & $\mathbf{5 . 2}^{\mathrm{a}}$ & $\mathbf{4 . 0}^{\mathrm{a}}$ \\
\hline M2 & $1 / 2 \mathrm{MS}$ & $4.8^{\mathrm{ab}}$ & $3.3^{\mathrm{a}}$ \\
\hline M3 & KC & $4.0^{\mathrm{b}}$ & $2.7^{\mathrm{b}}$ \\
\hline \multicolumn{2}{|c|}{ CV (\%) } & 4.20 & 4.54 \\
\hline
\end{tabular}

* Means followed by same letters within a column are not significantly different according to Duncan's Multiple Range Test at $\mathrm{P} \leq 0.05$ level.

In the M1 treatment, the average height and leaf number of shoots cultured on MS $1 / 2$ is highest with $5.2 \mathrm{~cm}$ and 4 leaves per shoot, respectively, next to the $1 / 2 \mathrm{MS}$ and $\mathrm{KC}$ medium. The height and leaf number of shoots was lowest on M0 treatments with MS mineral medium and the shoots grew weak and generated callus. A study of melon showed that the optimal rooting medium is the $1 / 2 \mathrm{MS}$ medium without plant growth regulators with the survival percentage of plantlets up to $100 \%$ (Huijun et al., 2011; Wei et al., 2005). However, this investigation shows that the growth of shoots is suitable with the MS $1 / 2$ medium.

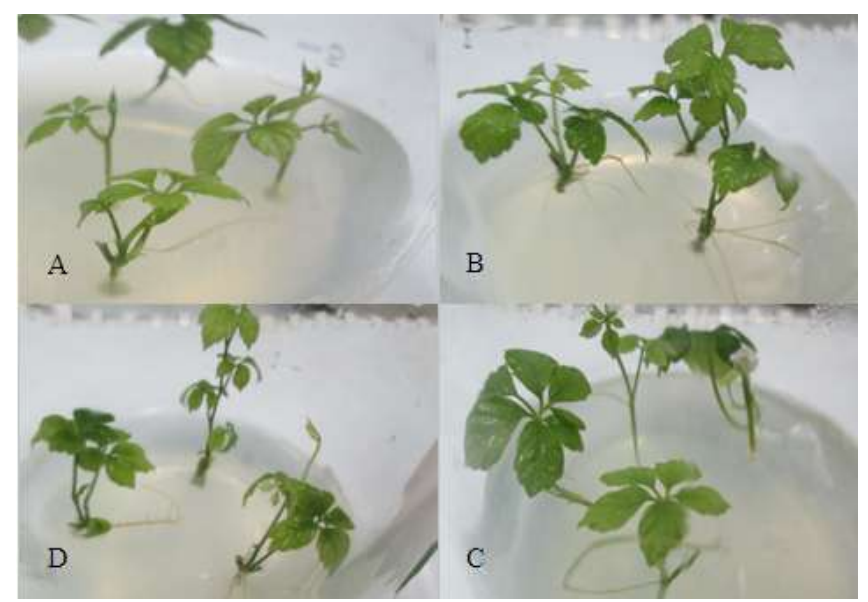

Figure 3. The growth of the Giao Co Lam shoots on different mineral medium. (A) MS, (B) MS 1/2, (C) 1/2 MS, (D) KC.

\section{$D$. The effect of the concentrations of IBA on the rooting of Giao Co Lam}

The experiment was conducted by selecting the $2 \mathrm{~cm}$ long shoots and cultured in the medium supplemented with different concentrations of IBA after 6 weeks of incubation. The results in Table 4 shows the highest root length and number of roots in treatment R1 with $7.6 \mathrm{~cm}$ and 6.4 roots per plantlet, respectively. In this study, the control treatment without IBA shows the number of roots and root length lower than that treatment with the concentrations of 0.25 $\mathrm{mg} / \mathrm{L}$ and $0.5 \mathrm{mg} / \mathrm{L}$. At the higher concentration of IBA (1.0 $\mathrm{mg} / \mathrm{L}$ ), the number of roots and root length is lower than that of the control treatment. Therefore, the optimal concentration of growth regulators for each specific objective needs to be determined for root formation. 
Proc. of The Sixth Intl. Conf. On Advances in Applied Science and Environmental Technology - ASET 2017 Copyright (C) Institute of Research Engineers and Doctors, USA .All rights reserved.

ISBN: 978-1-63248-119-1 doi: 10.15224/ 978-1-63248-119-1-36

TABLE 4. EFFECT OF IBA CONCENTRATIONS ON ROOT FORMATION OF SHOOT

\begin{tabular}{|c|c|c|c|}
\hline Treatment & $\begin{array}{c}\text { Concentration of } \\
\text { IBA }(\mathbf{m g} / \mathbf{L})\end{array}$ & $\begin{array}{c}\text { Root length } \\
(\mathbf{c m})\end{array}$ & Root Number \\
\hline R0 & 0.00 & $4.5^{\mathrm{c}}$ & $3.2^{\mathrm{c}}$ \\
\hline R1 & $\mathbf{0 . 2 5}$ & $\mathbf{7 . 6}^{\mathrm{a}}$ & $\mathbf{6 . 4}^{\mathrm{a}}$ \\
\hline $\mathrm{R} 2$ & 0.50 & $5.4^{\mathrm{ab}}$ & $5.2^{\mathrm{ab}}$ \\
\hline $\mathrm{R} 3$ & 1.00 & $4.2^{\mathrm{c}}$ & $2.8^{\mathrm{c}}$ \\
\hline \multicolumn{2}{|c|}{$\mathrm{CV}(\%)$} & 6.61 & 10.07 \\
\hline
\end{tabular}

* Means followed by same letters within a column are not significantly different according to Duncan's Multiple Range Test at $\mathrm{P} \leq 0.05$ level.

According to Zhang et al. (1989) and Wang et al. (1992), the shoots of Giao Co Lam cultured on $1 / 2$ MS medium supplemented with IBA $(1 \mathrm{mg} / \mathrm{L})$ were suitable for the formation of roots. Another study showed that MS medium supplemented with IBA $(0.1 \mathrm{mg} / \mathrm{L})$ is appropriate for rooting of Giao Co Lam shoots $(100 \%)$ and the number of roots per shoot reached 4.16 (Lam et al., 2015). The studies showed that there are different in the concentration of different growth regulators affecting the root formation of of Giao Co Lam. In this study, the number of roots and root length formed on MS $1 \frac{1}{2}$ medium added with $0.25 \mathrm{mg} / \mathrm{L} \mathrm{IBA}$ is higher than that of previous reports.

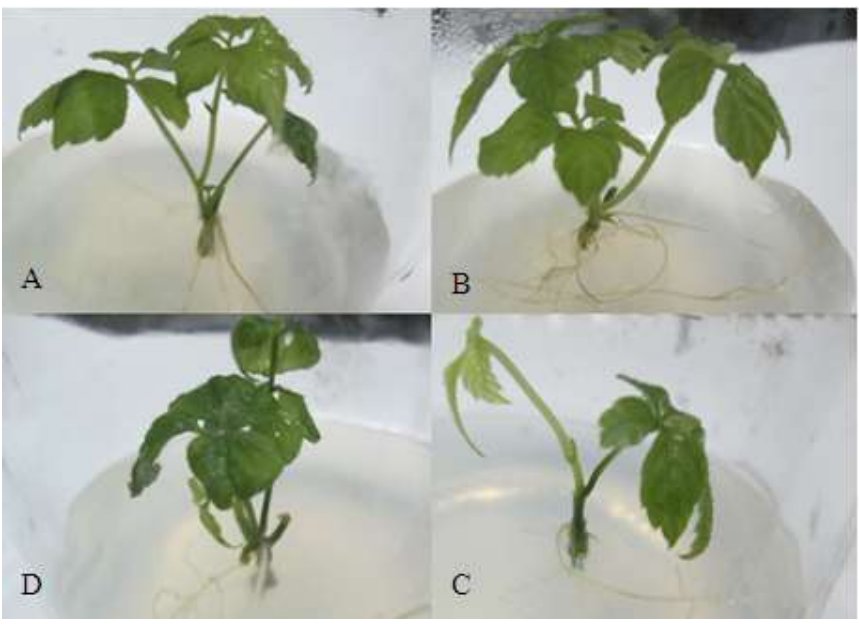

Figure 4. The rooting induction of the Giao Co Lam shoots on media supplemented with IBA at different concentrations. (A) Control, (B) 0.25 $\mathrm{mg} / \mathrm{L}$, (C) $0.5 \mathrm{mg} / \mathrm{L}$, (D) $1.0 \mathrm{mg} / \mathrm{L}$.

Plantlets fully developed with stems, leaves and roots will be transferred to the nursery. This is the most difficult stage in the in vitro propagation techniques, especially for herbaceous plants. The shoots transplanted into the rooting medium for 6 weeks will be transferred to natural conditions from 1-2 weeks for acclimation. The plantlets were removed from the bottle, washed and planted with high density on the foam tray $(58 \times 36 \times 12.5 \mathrm{~cm})$ containing clean soil (Tribat) covered with plastic from 7-10 days. And then, the plantlets were removed from the tray and planted on beds with black mesh cover. The rate of survival plantlets after 2 months is $85 \%$.

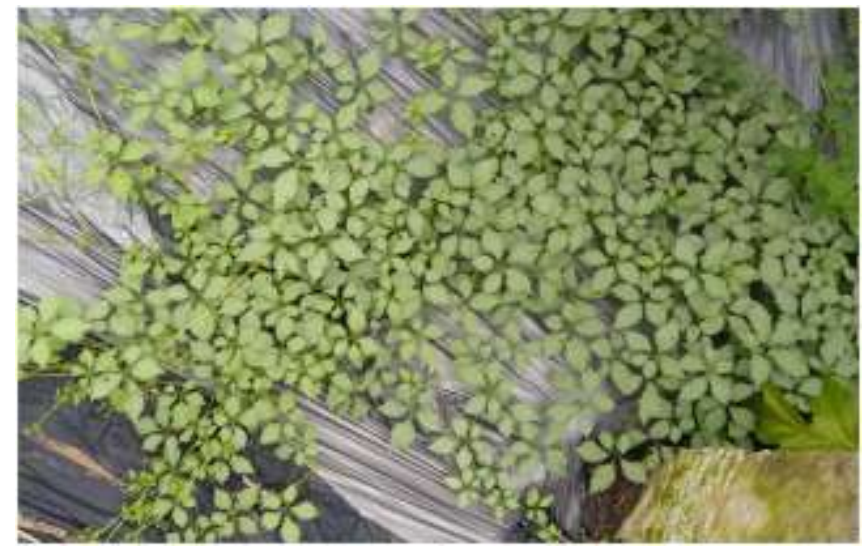

Figure 5. Giao Co Lam were transferred the garden after 2 months.

\section{Iv. Conclusion}

Based on the investigation micropropagation of Gynostemma pentaphyllum, we determined that concentration of javel solution $(\mathrm{NaOCl} 5 \%)$ and aseptic time suitable for sterilizing the explants to establish the in vitro culture were $50 \%$ and 20 minutes, respectively; the appropriate concentration of plant growth regulators for the generation and multiplication of shoots is BA $(1.0 \mathrm{mg} / \mathrm{L})$ and NAA $(0.1 \mathrm{mg} / \mathrm{L})$, the suitable mineral medium for the growth of shoots is the MS $1 / 2$; the suitable concentration of IBA for the rooting of in vitro shoots is MS $1 / 2$ medium supplemented with $0.25 \mathrm{mg} / \mathrm{L}$.

\section{References}

[1] Blumert, M. \& Liu, J.L. (1999), Jiaogulan China's 'Immortality', Herb, Torchlight Publishing Inc., Badger, USA.

[2] Huang, S. C., Hung, C. F., Wu, W. B., Chen, B. H. (2008a). Determination of chlorophylls and their derivatives in Gynostemma pentaphyllum Makino by liquid chromatography-mass spectrometry. Journal of Pharmaceutical and Biomedical Analysis, 48(1), 105-112.

[3] Huijun, Z., Gao, P. \& Luan, F. (2011). Efficient plant regeneration from cotyledonary node explants of Cucumis melo L. African Journal of Biotechnology, 10(35): 6757-6761.

[4] Kiem PV, Ky PT, Huong PT, My TK, Anh PT, Minh CV, Cuong NX, Nhiem NX, Jae-Hee H, Hee-Kyoung K \& Young HK (2009), Dammarane-type saponins from Gynostema pentaphyllum and their cytotoxic activity, Vietnam Journal of science and technology, 72A: $71-78$.

[5] Lam BD, Tinh NT, Duy NV, Bao NV, Hien LV, Binh Truong NX (2015). Investigation of Giao Co Lam propagation (Gynostemma pentaphyllum Thunb) using in vitro culture technique, Journal of agriculture and rural development, 21 (7): 249-256.

[6] Norberg, A., Hoa, N.K., Liepinsh, E., Van P.D., Thuan N.D., Jörnvall H., Sillard R. \& Ostenson C.G. (2004), A novel insulin-releasing substance, phanoside, from the plant Gynostemma pentaphyllum. J Biol Chem., 279 (40): 41361-7.

[7] Razmovski-Naumovski, V., Huang, T., Tran, V., Li, G., Duke, C., \& Roufogalis, B. (2005). Chemistry and pharmacology of Gynostemma pentaphyllum. Phytochemistry Reviews, 4(2): 197-219.

[8] Shi XG (2007) Fast propagation and polyploidy induction of Gynostemma Pentaphyllum (Thunb.) Makino. Thesis of Master, Southwestern University.

[9] Wei, X., Wei, J., Jiang, Y., Tang, H., Li, F. \& Ye, W. (2005). Study on the cultivation of Gynostemma pentaphyllum with plantlets of tissue culture, Journal of Guangxi Academy of Sciences (2): 253-261.

[10] Wang, L., Yang, M., Li, K. (1992). Tissue culture and cytohistology studies in Gynostemma pentaphyllum (Thunb) Makino. Journal of Beijing University (Natural Science) (1), 149-158. Zhang Z.H., Liu H., Zhao L.H., Han X.Z. (1989), Clonal propagation of Gynostemma pentaphyllum (Thumb.) Makino in test tubes, J Chinese Material Medicine, 4(6): 335-6, 382. 